\title{
Three Evidence Explicating the Visual Dimensions of Music
}

\author{
Arugha Aboyowa Ogisi \\ http://dx.doi./org/10.4314/ujah.v20i1.6
}

\begin{abstract}
Music is an aural art because it uses organized sound as the medium for the several roles that it plays in society including but not limited to validation of social institutions, reinforcing culture, as culture, for catharsis, socialisation, education, therapeutic and communication, among others. Through the ages, the perception of music as an exclusive aural art has been perpetuated in literature that it appears invisible. However, it is not only at the sonic level that it functions. Data from this study came from observation of musical performances and audience behaviour in several contexts and study of the definitions of music in extant literature. When observed closely, one finds that it has a visual element as attested to by response to aesthetic appreciation of musical performances, linguistic expressions, and preferential response of market forces for audio-visual recordings than audio recordings. These examples question the long held perception that music is entirely a sonic art whereas it is not so. It is therefore imperative to re-examine and redefine music as an art that is not just aural but with an audiovisual component.
\end{abstract}

Keywords: Aural, Audio-visual Art, Music, Sonic Art, Visual Art.

\section{Introduction}

The title of this paper evokes an absurdity because it presents music, a widely known aural art as also a visual art. However, music in African musical parlance is a sonic art presented within a 
multimedia context (Tracey 1962). Euba (1976:30) aptly captures this thought when he states that "Nigerian traditional music, in common with traditional music from other parts of Africa, have a strong visual element arising from the customary presentation of much of this music in association with extra-musical and even extra-artistic events". The classification of an object or subject is a reflection of its components, or perception of its attributes. There are various types of relationships viz the genetic, social, commercial. The terms used to express these relationships reveal the cleavage between members of society. Life is a conglomeration of relationships and the way relationships are navigated is predicated on the perception of the realities of the relationship.

However, perception is dependent to a great extent, on knowledge and understanding. While understanding of a subject matter is dependent on the quantum of knowledge concerning the component parts and understanding deepens, so does perception. Perception is also infinite because there is always the unknown, the new frontier. So knowledge is incremental such that man knows, perceives, and understands in part and is never total. There is therefore, an ever increasing quest for knowledge about existential issues.

\section{The Nature of Music}

Music is a multi-dimensional art because it functions at various levels in society where it is classified severally depending on the perception or concerns of the enquirer. But it has long been regarded and classified as an art because of the similarities between it and other disciplines. However, it has its own distinct features some of which are well known and others not widely known. For example, music is well known to be an aspect of culture or as culture (Nettl, 1956, Merriam 1964, Herndon and 
McLead 1982, Elliott 1990 and Wade, 2008); it affects us psychologically (Seashore, 1937, Meyer 1956, Farnsworth, 1958, Deutsch, 1984, Scherer, 2001); it is sociological (Núñez, et al. 2002,DeNora 2003, Hennion, (2003); it is philosophical (Spitzer, 2006,Gracyk (2011); and it is therapeutic (Fukui, 2008). These apart (Howell, et al., 2003) states that 'Music has been shown to have beneficial effects on humans ...' [and affects] the behaviour of captain chimpanzees and found that music had significant positive effects, including a reduction in agitated and aggressive behaviours. Several studies have shown that music affects living things (humans, animals and plants).It affect Literature portrays that it does these by its nature as a sound art.

However, the fact remains that music is most widely known as an art which proceeds from creative activities with its unique features. The plastic arts are tangible and complete on creation, the performance arts are temporal and require an intermediary, a performer to be between the creator and the consumer. The performer does this anytime the music is required. Although recording has ameliorated the need for this, one cannot really regard the playing of a recorded work as performance because it is a replay of an earlier performance: a plasticised presentation of an earlier performance.

The aesthetic pleasures that an audiences derive from a musical performance is not just from the aural presentation of the music but also comes from the visual presentation, i.e. 'seeing' the actions involved in bringing the music into being. The performative skills that are required include such acts as manipulating an instrument, playing a piece flawlessly at breath taking tempo, the overall empathy of the ensemble as makes his/her contribution of each member to realizing the music, the experience of being immersed in the sound so produced, watching 
the uniform bowing of the string section of an orchestra, the command and control of an orchestra by the conductor and how he/she draws out the desired tempo, dynamic and expression, and the concentration required to produce the music among several others are some of the compelling reasons that inform attendance to concerts, gigs, operas, and other types of musical events globally.

Although music has been a subject of interest to scholars for ages, most definitions are anchored on the aural aspect and thereby enthroning the idea that music is solely a sonic art. A few examples are sufficient to prove the point. Crystal (1997:737) defines music as "an orderly succession of sound of definite pitch, whose constituents are melody, harmony and rhythm". McGlynn (2001:657) states that "music is the art of combining sounds into a coherent perceptual experience, typically in accordance with conventional patterns and for an aesthetic purpose." Then for the World Book Inc (2004:946), "music is sound arranged into pleasing or interesting patterns. It forms an important part of many cultural and social activities." A very popular definition of music from late 1960s to resent times, is that "it is sound pleasant to the ear". Although this definition has been discredited, it shows how deep rooted the sonic perception music is in the society.

The perception that music is an aural art form has endured through time that it appears invincible. However, it is flawed because it ignores one of its important components - the visual aspect. Sound is the raw material from which music is made but it is not the music, rather it is the manner sound is organised, and performed that transform it to music. It is the performance, and audio-visual activities associated with making the sound and transforming it to music, that is the main attraction in musical 
performances. We shall now proceed to show evidence that support our assertion.

\section{The Performance Evidence}

The applause, be it spontaneous or organized, is a universal means of appreciating performance, it is usually shared by the composer and the performer. As a physical activity, music performance involves skilful manipulation of the sonic medium; this fascinates humans and draws them to music performance.

A masterful rendition by an accomplished performer elicits spontaneous audience applause is a means of sharing in the achievement, and participating in a communion that the performer facilitates and tacitly invites the audience to partake of. As the performance proceeds, the invitation to the audience to participate intensifies and becomes compelling that the audience is transformed that it becomes one with the performer. At this stage the appropriate response to the invitation is one or more of the following: To clap in synchronized timing with the music being performed, or shouts in joyous acclamation or in extreme cases when a member of an audience is enthralled he/she physically moves from the audience side of the performer-audience divide to join the performers (Enekwe 1991). The level of involvement of an audience depends on the intensity of the communion that the performer creates. In African musical arts parlance, the success of a performer is, in part, measured by this. Although the 'communion' is transient in the performance context, its effect extends beyond the moment to building social relationships in the community. In this sense we aver that an important role of musical performance in Africa is the creation, and sustenance of community. Indeed, musical performance bridges social barriers, reinforce shared values, strengthen interpersonal relationships and 
lay bare our common humanity. So the response of an audience to an excellent musical performance is in other sense a celebration of shared values and experiences.

However, it should be emphasized that the purpose of all types of performance is to communicate. The means through which this is established and maintained is determined by the type of art. In music, communication is done through the sonic medium in singing or playing of instrument, and gestures, facial expressions, movements, etc. The effectiveness of the communication is dependent on how adept the musicians are in using these media. In another sense to say that a musician communicates means that he has a message which makes him/her a messenger. A message may be word borne as in song or expressed in mood as in instrumental pieces. So music as an art is a means of communication through the sonic medium but facilitated by visual aspects. It is therefore not exclusively a sonic art; rather, it has a visual component that enhances the sonic presentation. Indeed it is upon the visual aspects that the entire architecture of the musical performance based industry rests; such that a musical performance devoid of its visual aspects is insipid, bare, completely lacking in flavour and devoid of its essence.

\section{The Linguistic Evidence}

Meanwhile, literature points to music as an exclusive sonic art even when linguistics evidence points otherwise. Language as a means of communicating thoughts, experience, reality and even its abstractions, it is a reflection of reality as opposed to the absurd. It may, to some extent, offer insights into the inner recess of the unconscious. We shall therefore proceed to examine the perception that language usage conveys about what music is. 
When someone makes a point about the virtuosity of a pianist who performed at a concert that he attended, it is usual for him/her to say "I watched Mr Jones play Fur Elise on the piano at the concert" not 'I heard Mr Jones play Fur Elise on the piano at the concert.' If it was a radio programme it is normal for a speaker to say 'I listened to Mr Jones playing Fur Elise on the radio', if it were a television programme he would say 'I watched Mr Jones playing Fur Elise on the piano'. If in the course of the performance someone (A) stands in front of another person (B), from seeing the performer on the stage, it is usual for B to say to A 'Please, you are blocking my view?' Again, it is another scenario if a lady is to inform her friend that she attended a musical performance, she may choose to say 'I went to the show'. By referring to the event as a 'show' means that the event was an exhibition, a display in obvious reference to the visual aspect of the musical experience; one does not say 'I went to hear the show'. These examples point to the fact that musical performance has a visual component that trills us, a wonder that we cannot thoroughly explain. Music is best appreciated within its audio-visual component which is reflected in the above examples. These examples clearly prove that music has a visual component that has so far been undermined.

\section{Evidence from Recording}

Since the advent of music videos, the sale of audio recorded music products has plummeted because audio recording is an incomplete representation of the musical experience and just a documentation of the aural aspect. This was the case because the technology to capture both the visual and aural components of the music was yet to be developed. However, when audio-visual recordings became available, people could experience the two aspects of musical performance - the audio and the video angles of music that they 
were no longer pleased with the one-sided product which audio recordings represent, and the purchase of audio recordings declined; thus confirms our assertion that music has a visual component. In music it is the 'seeing' the visual that makes the hearing (the audio) meaningful. Music and indeed all the performance arts are highly visual. As we have mentioned earlier, it is the manner that the performer manipulates the sonic medium, the 'doing', which fascinates an audience and attracts them to performances. Audio-visual recordings enable audiences to have the visual experience of a performance so that musicians perform on specially lit and raised stages while the audience sits on raked platforms. It is also for the visual component that a musician practices for long hours to master the music to enable him/her to perform flawlessly to justify the money and time that audiences expend to attend performance events.

It is in this regard that Blackings (1977) definition of music as "humanly organized sound" comes to the fore. Like other extant definition it recognizes that sound is the material of which music is made but went further to emphasize the importance that organization plays in the process. It is the organizing that takes place that transforms the sound into music. The organization aspect is at two levels: the formative or ideation level and the realization or performance level. Ideating is imaginative; it is the creative or bringing to being, a task for the composer. It often involves writing down the music usually by a composer who is skilled in the use of notation or it may also be unscripted where in the idea exists in the mind of the composer. It is noteworthy that most music in the world are not notated or transcribed just as most thoughts are also not written. So, in this respect, both music and language exist similarly in nature. It must be mentioned that notation is a means of documentation for easy retrieval to curtail variations occasioned 
by memory failure or loss. However, the growth of formal education and its association with literacy, the ability to write one's thought in a system of notation and the ability to decode it, has taken on a status symbol that has characterized society through human history. Literacy in western civilisation was initially restricted to clerics but as educational thought developed, literacy became a major component of human development and this ultimately led to advocacy for universal literacy, and writing became a coveted attribute of the learned. With the elevation of literacy above orality, societies have strived to become literate with the result that there is no time in human history where the world has more literate people than today, and it is growing by the day. Going by the law of supply and demand, one would have expected the quest for literacy to lose value because of the abundance of literate individuals, but on the contrary, literacy has become a coveted skill that is fit and proper of persons of standing in society, so that an elitist air Sour rowed the literate. By the 19th century however, the written word had taken on an enhanced status over the spoken word. It is not that the written word is more profound than the spoken word, but because it is written gives it a seeming permanence, a mystic that conferred superiority status on it.

With respect to music, notated music came to be more highly prized than music in oral tradition. Meanwhile, the fact remains that a notated piece of music is neither reflective of its quality nor is it a measure of superior craftsmanship or profundity. As we mentioned earlier, notation is no more than a means of documentation and preservation in order to reduce variations, especially in music, an art where such is rife and very significant. The fact remains that most of the music traditions in the world are created, and performed without recourse to notation. Music is a living art that survives primarily in the heart of man. Beautiful 
music remains beautiful irrespective of it being documented or otherwise. Rather, musical beauty results from the creative potency of the composer, the aesthetic standards that are set by the culture, the performance ability of the performer and the receptivity of the audience among others.

During ideation, the composer organizes the sound material and creates the intended music, but the work cannot be appropriately referred to as music because it is yet to be heard. At this stage the music exist as idea in the mind of the composer or as a score. Musical notation is therefore "merely a guide or a point of reference" (Samana 2005:30). Until it becomes sound, it exists in the mind of the composer as 'conceived sound' just as Euba (2005:84) notes that "compositions written in staff notation are merely prescriptions for music making and have no life until they are performed" a view also echoed by Dodd (2013). It is the duty of the performer to transform the conceived sound i.e. the notation, into musical sound. So composers require the performer to realise music that is scored. The process or act of realisation is interpretative because the performer takes the composer's idea and express it in his/her own terms subject to the performance perception and understanding of the composer's intention; the performance practice of the genre, period or style of the music. The performer may be a soloist or an ensemble. In works for solo voice the performer is at liberty to interpret it as he/she deems fit. In ensemble work, there is usually a conductor whose duty is to assist the performers in an ensemble (orchestra, choir, opera band etc) to realize the intentions of the composer. However, it is mostly in literary or pseudo-literary music traditions that conductors exist. In oral tradition, the divide between the creator and the performer is almost non-existent, in fact the composer is often the performer thereby eliminating the need for an intermediary-the conductor. 
Thus, musical performance and indeed all types of performance are stylistic because musical style in itself is a constitute part of the musical identity of a performer thus peculiar to the performer. As the individual trait of a performer influences his/her performance, there are differences between the renderings of a work by different performers due mainly to nuances in interpretation. Interpretation is a creative process that has not received sufficient scholarly attention particularly in this clime where oral tradition remains the dominant means of performing, preserving and transmitting music.

The process of composing music has nothing attractive about it. It is mainly a reclusive preoccupation that causes composers to hover between the narrow prescient of sanity and insanity. However, the interpretative stage is awesome. Because of individual margin of differences in interpretation, between performers audiences come to associate conductors or solo performers with personal styles which invariably becomes a determining factor in attendance to their performances. For some artistes their style become so loved by the public that tickets to their performances are sold out well ahead of the event.

One of the major attractions to sold out concert events is the experience of 'seeing' the musician making the music, the visual experience of being there when the music was being recreated, the transformation from idea to music, watching the event when the production process (the performance) becomes one with the product (the music). This is the mystic and attraction of watching a musical performance. There is need for deeper reflection on this aspect of the musical art. As we have demonstrated here, music is beyond the aural experience that scholars have pursued relentlessly through time. Music is also visual; indeed it is an audio-visual art. 


\section{Conclusion}

We have attempted in this brief paper to draw attention to the fact that music is more than its aural aspect that literature have tenuously emphasized for ages, but that it also has a visual element as attested to by performance situations, linguistic expressions, and market response to audio-visual recordings. It is my considered view that there is a need for a re-definition of music that puts in proper perspective the over sighted dimension. Suffice it to say that music is a sonic art with visual attributes expressed in performance.

\section{Arugha Aboyowa Ogisi \\ Department of Music \\ Delta State University, \\ Abraka \\ madamedun@yahoo.com}

\section{References}

Blacking, J. (1977). How musical is man? Washington: University of Washington Press.

Crystal, D. (1997). The Cambridge encyclopedia: Cambridge: Cambridge University Press.

DeNora,T. (2003). After Adorno Rethinking Music Sociology. In: the Press Syndicate of the University of Cambridge.

Diana Deutsch, (1984). "Psychology and Music.” In: M. H. Bornstein (ed.). Psychology and its Allied Disciplines. Hillsdale: Erlbaum, 155-194.

Dodd, J. (2013). Is John Cage's $4^{l} 33$ Music" Retrieved from https://www.youtube.com/watch?v=WTCVnKROlos on $14^{\text {th }}$ January, '2015.

Elliott, D. J. (1990). "Music as Culture" Toward a Multicutural Concept of Art Education. Journal of Aesthetic Education, Vol. 24(1), special issue: Cultural Literacy and Art education 
(Spring) 147-166. Published by University of Illinois Press. Retrieved from http://www.jstor.org /stable/3332862 on $4^{\text {th }}$ May, 2017. 10:48 UTC

Enekwe, O. O. (1991). Theories of dance in Nigeria: an introduction. Nsukka: Afa Press

Euba, A. (2005). "Remembering Joshua Uzoigwe: Exponent of African pianism (1946-2005)."Journal of the musical Arts in Africa 2:1, 84-88. Accessed from https//doi.org/10.2989/18121000509486703 on 24 December, 2017.

Farnsworth, P. R. (1958). "The social psychology of music 18991978. ” Topics Music. Publisher New York, Dryden Press.

Fukui, H. and Toyoshima, K.(2008). Music facilitate the neurogenesis, regeneration and repair of neurons. Medical Hypotheses Vol. 71, (5): 765-769.

Gracyk, T.(2011). Philosophy of Music. Oxford Bibliographies Your Best Research Starts Here. Retrieved from https://www.oxfordbibliographies.com/view/document/obo9780199757824/obo-9780199757824-0061.xml on 28/05/2019.

Hennion, A. (2003). "Music and Mediation: Towards a new Sociology of Music.” The Cultural Study of Music: A Critical Introduction, London, Routledge, pp.80-91.

Herndon, M. and McLeod N. (1982). Music as Culture Norwood, Pennsylvania: Norwood Editions,

Howell, Sue et al. (2003). "A stereo music system as Environmental Enrichment for Captive Chimpanzees." Lab Animal Vol. 32 (10):31-36.

Hugh, T. (1962). "The arts in Africa, visual and aural." African Music 3 , No.(1)

McGlynn, H. (2001). The Hutchinson Encyclopedia. Oxford; Helicon Publishers Ltd. 
Merriam, A. P. (1964). The anthropology of music. Evanston, Northwestern University Press.

Meyer, L. B. (1956). Emotion and meaning in music. Chicago II: University of Chicago Press.

Nettl, B. (1956). Music in Primitive Culture. Cambridge: Harvard University Press.

Núñez, M.J., Paula Mañá, David Liñares, María P. Riveiro, José Balboa, Juan Suárez-Quintanilla, Mónica Maracchi, Manuel Rey Méndez, José M. López, Manuel Freire-Garabal (2002). "Music, Immunity and Cancer."Life Sciences 71: 1047-1057.

Robert, F. (1988). The perception of music, trans. W. Jay Dowling.Hillsdale N. J.: Eribaum.(originally published as La Perception de la musique Paris: J. Vrin, 1958).

Samana, L. (2015). The meaning of music.Amsterdam:Amsterdam University Press. ProQuest Ebook Central. Retrieved from http://ebookcentral.proquest.com/lib/reading/detail.action?doc $\mathrm{ID}=4460742$ on $21^{\text {st }}$ October 2017.

Scherer, K. R. and Zentner, M. R. (2001). Emotional effects of music: production rules. Oxford; New York: Oxford University Press.

Seashore, C. E. (1937). "The psychology of music". Music Educators Journal. Vol. 23 issue: 4, page(s): 30-33 https://doi.org/10.2307/3385146

Spitzer,M. (2006). Music as Philosophy: Adorno and Beethoven's Late Style. Bloomington: Indiana University Press.

Tan, Leonard(2010). Thinking Musically: Experiencing Music, Expressing Culture, 2nd ed. by Bonnie Wade. Music Educators Journal Vol. 97.

World Book Inc. (2004). The world book encyclopaedia: Chicago; World book, Inc P. 